\title{
Energy-efficient solutions for household wastewater treatment using biofilters
}

\author{
Elena Gogina and Olga Yantsen* \\ Moscow State University of Civil Engineering, Yaroslavskoe shosse, 26, Moscow, 129337, Russia
}

\begin{abstract}
To maintain a comfortable life it is necessary to pay special attention to environmental aspects. This issue is as relevant for small towns as it is for big cities. The most important tasks are studies of wastewater treatment based on the principles of energy efficiency. The article presents research on the choice of loading material (methods of selection and analysis of loading material). Also described is effective wastewater treatment technology from nitrogen compounds, methods of intensification of the biofilters. Technological schemes are given. The main attention is paid to the study of the four-zone scheme, in which the processes of denitrification-nitrification occur sequentially. Along with the control reactors with the sanitary and chemical analyses, implemented regular monitoring of the microbiological investigations of biomass, using light and electron microscopy. An energy-efficient solution for deep wastewater treatment using biofilters has been developed. Calculation methods are given. The studies will significantly reduce the amount of energy consumed, the cost of processing precipitation. And the achieved effect of wastewater treatment will prevent eutrophication of water bodies and therefore reduce the cost of drinking water treatment.
\end{abstract}

\section{Introduction}

In the modern world, any technical solution should be based on the principles of maximum energy efficiency and environmental safety This is especially important in wastewater treatment.

In recent years, the requirements for the quality of water treatment have changed significantly, the flow rate attributable to the waste water treatment plants has changed and many stations require reconstruction.

A significant part of the low capacity waste water treatment plants in Russia includes biofilters $[1,3]$.

A biofilter is a plant in which water is filtered through a material covered with a biofilm formed by colonies of microorganisms. Peak construction of biofilters in Russia peaked in 1960.

Biofilters themselves do not require a considerable amount of energy. In the operation of biofilters power consumption is much lower than with other types of reactors, there is no need to use aerators, agitators and other energy-intensive elements.

\footnotetext{
*Corresponding author: YantsenOV@mgsu.ru
} 
The processes occurring in biofilters are close to natural. However, traditionally the treatment effect in them is lower than in other biological treatment reactors. Biofilters are quite simple structures and are often suitable for reconstruction, despite the long life.

Thus, the optimization of the biofilters is the relevant objective up-to-date. The main objective of the study is to achieve standards for discharges of treated water into water bodies.

\section{Materials and methods}

The study can be divided into several stages. Stage 1- preliminary, which tested the types of loading material. Stage 2- the main in the course of which the selected feed materials were used to study the processes of denitrification-nitrification in biofilters.

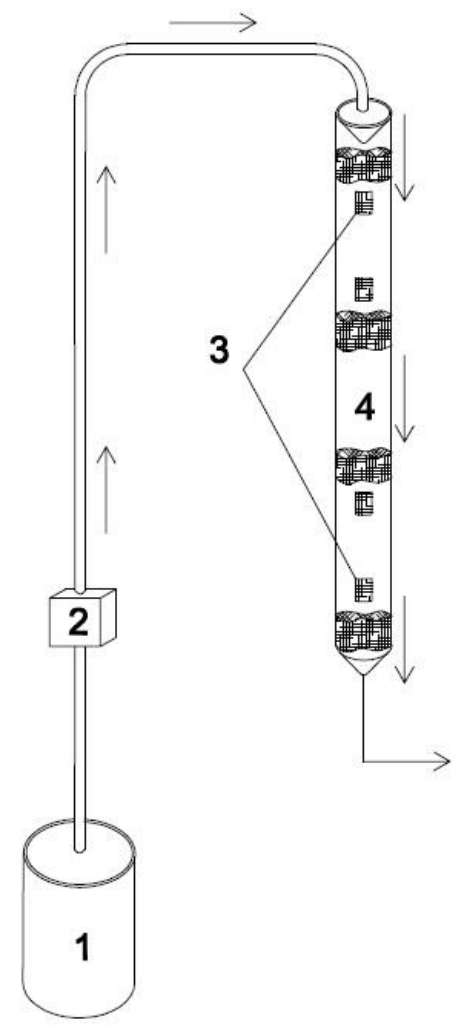

Fig. 1. The laboratory model of the biofilter (Stage 1): 1 - 60 liter cistern with waste water; 2 - Pump; 3 - inspection window, 4 - column of Plexiglas with a loading material located throughout the body of the reactor.

The experiment consisted of a laboratory model in the mode of a classical drip biofilter and determination of the contact time of the incoming water with the reactor body [1].

Stage 2- the laboratory model with 4 alternating zones of nitrification and denitrification was developed. The studies were carried out on artificial waste water based on pepton. 


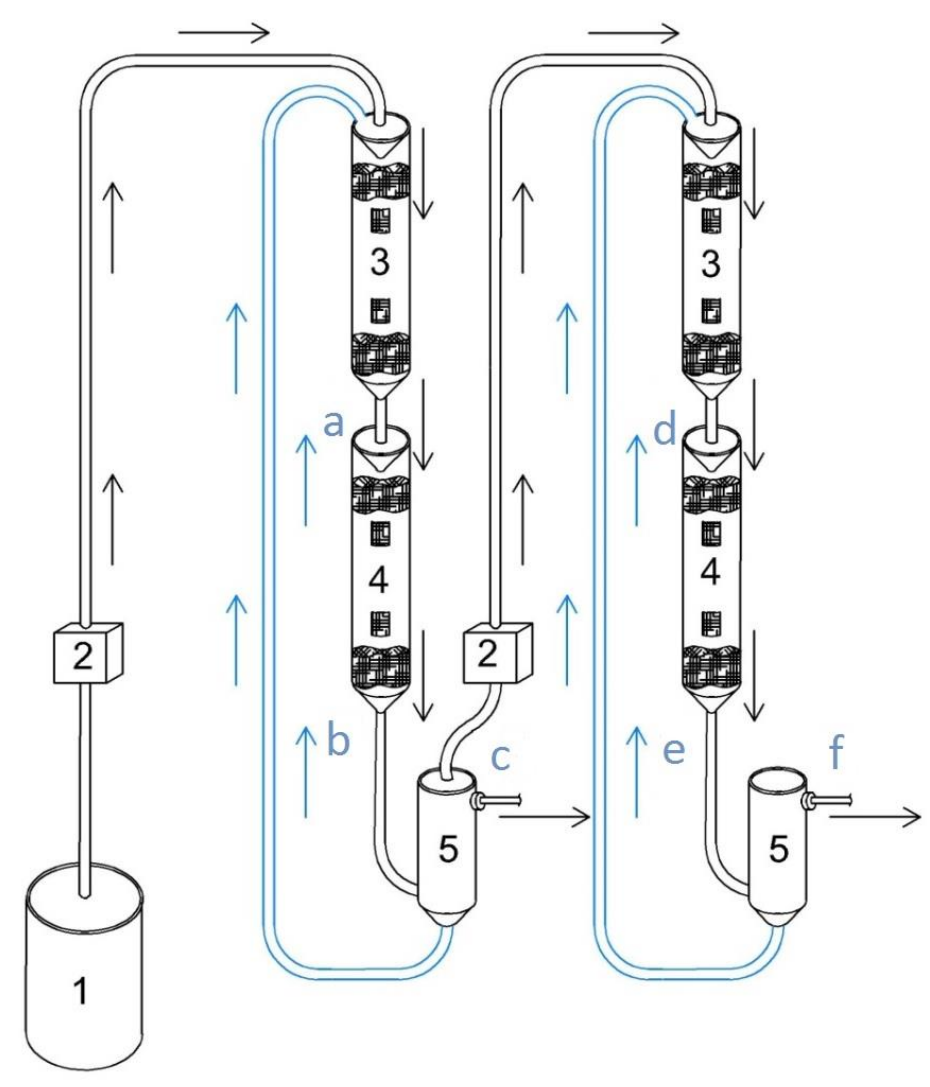

Fig. 2. The laboratory model of the biofilter( stage 2): 1 - 60 liter cistern with waste water; 2 - Pump; 3 - Anaerobic (anoxic) zone; 4 - Aerobic zone; 5 - Secondary clarifier.

Samples:

(1 step)

a - Waste water at the outlet of the first anaerobic (anoxic) zone;

$\mathrm{b}$ - Waste water at the outlet of the first aerobic zone;

c - Waste water after the settlement in the first secondary clarifier;

(2 step)

$\mathrm{d}$ - Waste water at the outlet of the second anaerobic (anoxic) zone;

$\mathrm{e}$ - Waste water at the outlet of the second aerobic zone;

$\mathrm{f}$ - Waste water after the setting-out in the second secondary tank

Aerobic zone was organized by natural aeration, without the use of additional aeration. In the anaerobic zone, air intake from outside is mechanically blocked, due to the location of biomass on the elements of the loading material, additional modifications, such as, for example, agitators, are not required. Which in itself is an energy-efficient solution.

Also in the technological scheme is realized by the recirculation of nitrate of water, which can significantly reduce the cost of operation of the bioreactor, regeneration of the biofilm and sludge handling.

Summarizing the above, we can conclude that the proposed pilot model will create a technological scheme that meets the high requirements for treated water. At the same time, the use of the studied technological scheme will reduce energy costs. 


\section{Waste water treatment on biofilters with alternating aerobic and anaerobic zones}

\subsection{Research of feed material}

Objectives of stage 1 of the research:

1. Study of the principal possibility of feed materials to immobilize the biofilm.

2. Study of features of formation of species composition and properties of biofilm.

3. Determination of the contact time of water with the body of the biofilter for each test feed material.

4. Selection of modification of the feed material for use in the biofilter.

The results are presented in figure 3

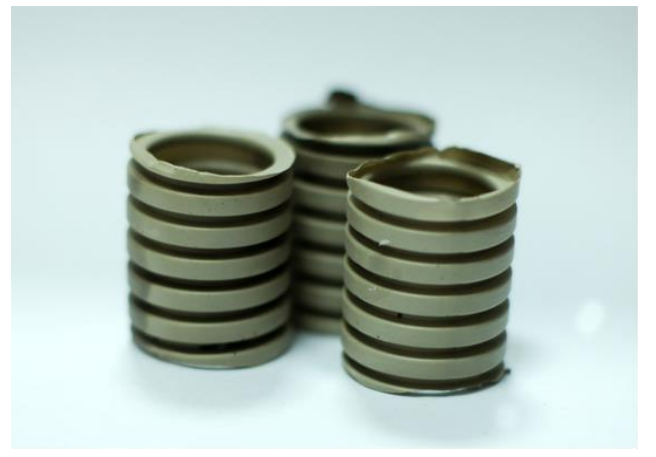

tubular feed material

BOD- $87.0 \mathrm{mg} / \mathrm{l}, \mathrm{NH} 4 \mathrm{~N}-9.3 \mathrm{mg} / \mathrm{l}$

Biofilm is in the upper and middle part of the biofilter, has the form of light brown mucous biomass

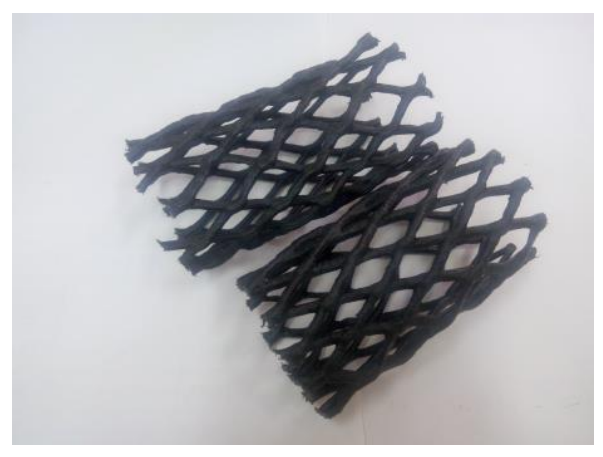

flat surface feed material

BOD- $16.0 \mathrm{mg} / 1, \mathrm{NH}_{4} \mathrm{~N}-17.9 \mathrm{mg} / \mathrm{l}$ Biofilm brown, is a thin layer throughout the loading material

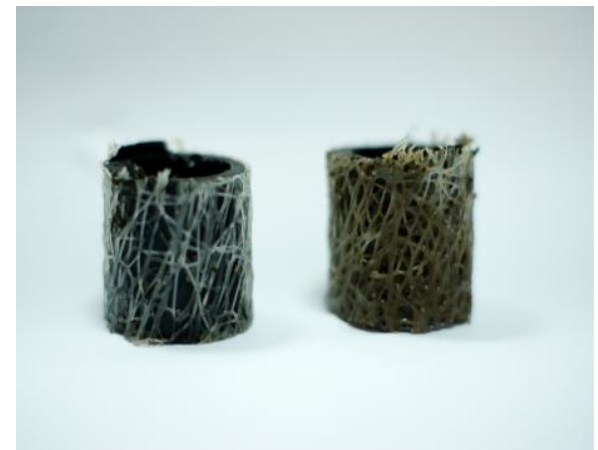

tubular mesh feed material

BOD- $18.0 \mathrm{mg} / 1, \mathrm{NH}_{4} \mathrm{~N}-1.8 \mathrm{mg} / \mathrm{l}$

Biofilm is located throughout the body of the biofilter, over time descends into the lower layers of the biofilter

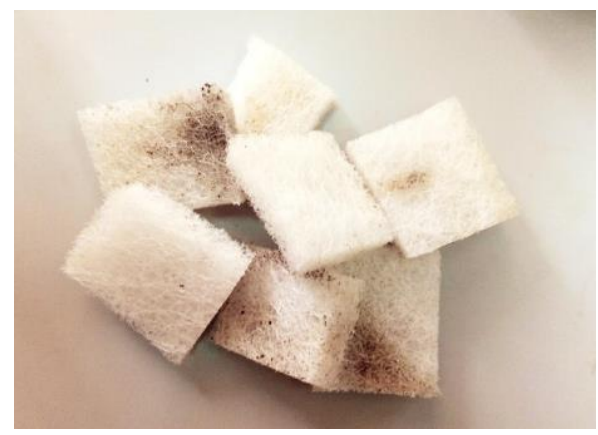

bulk feed material

BOD- $12.5 \mathrm{mg} / 1, \mathrm{NH}_{4} \mathrm{~N}-11.0 \mathrm{mg} / \mathrm{l}$ Biofilm is dark brown, located in the intercellular space of the feed material, dense mucous structure

Fig. 3. Feed. 
The research included additional test to define contact time of waste water with feed. The factor of time has a serious action upon biochemical processes in biofilters that means that intensity and efficiency of treatment also depend on the length of the path to pass by the drops of waste water on the feed's surface.

First a concentrated solution of dye was put into the lab model to define its concentration change in output water by means of photocolorimetry. The samples at the output were taken through the certain periods of time until coloration is absent.

Based on the results, graphs of the dye concentration dependence on the sampling time were constructed using a pre-built calibration curve, which is based on the results of determining the optical density of a number of standard dye solutions with different concentrations. Then the area of the figure obtained on the chart and the static moment of the plane figure relative to the ordinate axis are calculated.

Contact time was defined as the center of gravity of a flat figure [4].

\subsection{Studies of the pilot model with different feed materials}

Biofiltres were developed and actively built In Russia in 1960-70. Due to their construction, most biofilters are currently in usable condition. However most of them can provide only insufficient biological waste water treatment [2].

The norms of discharge of treated wastewater into fishery water bodies are presented in table 1. Therefore, the development of modern methods of biofilter reconstruction is necessary.Note that the process of eutrophication is reversible - reducing the concentration of pollutants leads to the normalization of the state of water bodies. This means that the proposed technology will improve the environmental condition of the environment.

Table 1. Pollutants values

\begin{tabular}{|c|c|c|c|}
\hline \multirow{2}{*}{ Factors } & \multicolumn{3}{|c|}{ Pollutants values $\lceil\mu \mathrm{g} / \mathrm{L}]$} \\
\cline { 2 - 4 } & $\begin{array}{c}\text { Incoming waste water } \\
\text { (Moscow region) }\end{array}$ & $\begin{array}{c}\text { After treatment in } \\
\text { biofilters }\end{array}$ & $\begin{array}{c}\text { Regulation } \\
\text { requirements }\end{array}$ \\
\hline BOD5 & $150-180$ & $15-20$ & 3 \\
\hline $\mathrm{NH}_{4}-\mathrm{N}$ & $20-25$ & $0,75-1$ & 0,39 \\
\hline $\mathrm{NO}_{2}-\mathrm{N}$ & -- & -- & 0,01 \\
\hline $\mathrm{NO}_{3}-\mathrm{N}$ & -- & -- & 9,1 \\
\hline
\end{tabular}

The biofilter is a biological treatment reactor, with fixed on the feed the biofilm. That's why choosing the feed material is very important. The feed material was researched in advance, selected 2 types of feed material: flat surface feed and bulk feed material.

Average results operation of a laboratory model in the work with the flat surface feed material shows in table 1 .

Table 2. Results (flat surface feed material)

\begin{tabular}{|l|c|c|c|c|}
\hline Samples & \multicolumn{4}{|c|}{ Pollutants values $[\mu \mathrm{g} / \mathrm{L}]$} \\
\hline & $\mathrm{NH}_{4}-\mathrm{N}$ & $\mathrm{NO}_{2}-\mathrm{N}$ & $\mathrm{NO}_{3}-\mathrm{N}$ & $\mathrm{BOD}$ \\
\hline Inlet waste water & 21.61 & - & - & 104.00 \\
\hline
\end{tabular}




\begin{tabular}{|l|c|c|c|c|}
\hline After 1st stage & 14.20 & 0.808 & 8.95 & 21.58 \\
\hline After 2nd stage & 0.63 & 0.15 & 5.86 & 3.28 \\
\hline
\end{tabular}

So there was a decision to replace the feed in the anoxic zones on the bulk feed material. Average results operation of a laboratory model in the work with the bulk and flat surface feed material shows in table 3 [5].

This is due to the low purification effect in these areas, and the state of biofilm. The aerobic biofilm zone thinly distributed over the whole volume of feed, biomass study by light microscopy revealed a large number of ciliates and rotifers, which were highly mobile. Presumably it is connected to peculiarities of feed structure and easy access to oxygen. The anoxic areas biofilm was unevenly distributed and has a "zone" of biomass growth During the study of biofilms was found that numbers of ciliates and rotifers are less than in the aerobic zone $[6,7]$.

Table 3. Results (flat surface feed material and bulk feed material)

\begin{tabular}{|l|c|c|c|c|}
\hline Samples & \multicolumn{4}{|c|}{ Pollutants values $[\mu \mathrm{g} / \mathrm{L}]$} \\
\hline & $\mathrm{NH}_{4}-\mathrm{N}$ & $\mathrm{NO}_{2}-\mathrm{N}$ & $\mathrm{NO}_{3}-\mathrm{N}$ & $\mathrm{BOD}$ \\
\hline Inlet waste water & 22.18 & - & - & 85.33 \\
\hline After 1st step & 11.19 & $0 ., 53$ & 11.03 & 12.95 \\
\hline After 2nd step & 0.31 & 0.03 & 5.86 & 3.01 \\
\hline
\end{tabular}

The investigated technological scheme can be used in the reconstruction of WWTP, especially in cases where the existing treatment plant scheme includes construction biofiltration where possible to achieve the required cleaning performance not only for BOD and nitrogen compounds [4].

\subsection{Studies of the formation of sludge}

Most of the energy consumption requires sludge treatment. An important advantage of biofilters over other types of reactors is a small amount of sludge.

Which is several times less than the dose of silt in reactors with activated sludge, which means much less energy will be spent on the treatment of sludge.
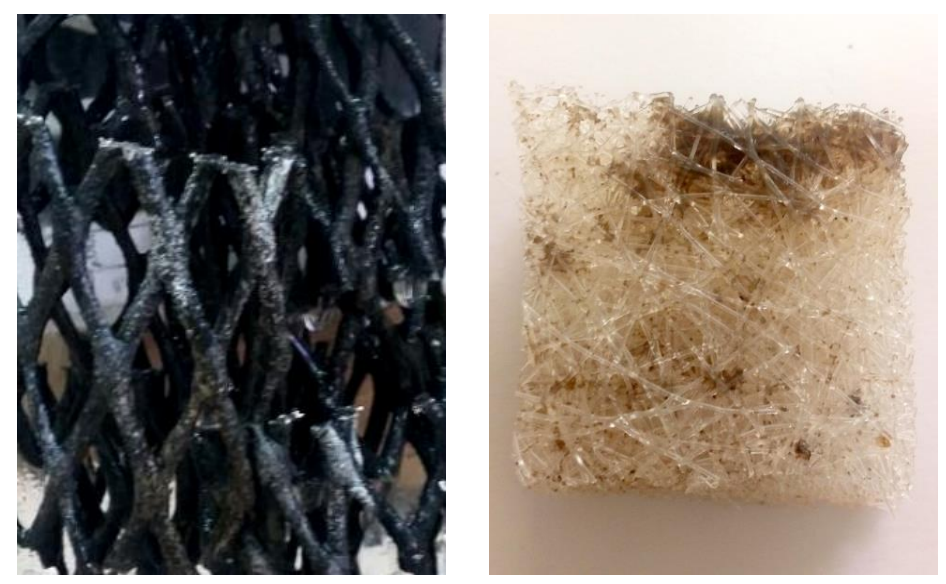

Fig. 3. Feed with biofilm. 


\section{Discussions}

The presented studies show a high degree of wastewater treatment from nitrogen compounds, but there is practically no treatment of incoming wastewater from phosphorus compounds. This is typical for biofilters. The authors propose to purify the waste water from phosphorus compounds by using the reagents after treatment the waste water to the biofilters. This will allow to achieve the necessary indicators while slightly increasing energy costs.

The results obtained are consistent with the work of scientists and indicate the relevance of further research to improve waste water treatment [8-10].

This work was financially supported by Ministry of Science and Higher Education of the Russian Federation (\#NSh-3492.2018.8).

\section{Conclusions}

1. Studies of the system of denitrification-nitrification using biofilters have shown the feasibility of its use for deep treatment of wastewater from nitrogen compounds with the provision of regulatory indicators for discharge into the reservoir of fishery importance.

2. Bioilters themselves do not require a considerable amount of energy.

3. Required less the cost of sludge handling in comparison with other reactors

4. When wastewater is treated to the above indicators, it requires much less costs for the preparation of drinking water.

\section{References}

1. E. Gogina, O. Yantsen Intern. J. Appl. Eng. Res. 10 (24) 44070-44074 (2015)

2. E. Gogina, O. Ruzhitskaya, V. Shmalko, MATEC Web of Conf. 17809015 (2018)

3. N. Makisha, O. Yantsen. J. Appl. Mech. Mat. 587-589 640-643 (2014)

4. R. Zyika, W. Dabrowski, E. Gogina, O. Yancen. J. Ecol. Eng. 19 (4) 269-275 (2018)

5. E. Gogina, O. Yantsen MATEC Web of Conf. 25103041 (2018)

6. E.S. Gogina, O.V. Iantcen, O.A. Ruzhitckaia, V. Dabrovski, D. Boruzhko, R. Zhilka J. Water and EcologyVolume 67 (3) 35-45 (2016)

7. E. Gogina, O. Ruzhitskaya, V. Shmalko J. MATEC Web of Conferences 17809016 (2018)

8. T. Ha Quan, E. Gogina, T. Van Quang J. MATEC Web of Conferences 25103029 (2018)

9. Gulshin, E.Gogina IOP Conference Series: Materials Science and Engineering 365(2), 022032 (2018)

10. Kulakov, N. Makisha, J. MATEC Web of Conferences 17809017 (2018) 